\title{
Lepra de Wade
}

\section{Wade's leprosy}

\section{Camila Iglesias Leal ${ }^{1}$, Liliana Olivares $^{2}$, Sofía Mazzaroni ${ }^{3}$, Eduardo Restifo ${ }^{4}$ y Esteban Maronna ${ }^{5}$}

\section{RESUMEN} \\ La lepra de Wade o lepra histioide (LH) es una entidad con hallazgos \\ clínicos, bacteriológicos e histopatológicos distintivos, considerada \\ una variante inusual de la lepra. Se caracteriza por la presencia de \\ tubérculos hipertróficos, un índice bacteriológico alto e histiocitos \\ ahusados y arremolinados en la histopatología. Se puede presentar \\ de novo 0 en pacientes con antecedentes de lepra luego de monotera- \\ pias con dapsona, tratamientos incompletos e, incluso, como recaída \\ posterior a esquemas terapéuticos completos. Se presenta el caso de \\ un paciente con lepra de Wade, que nunca había recibido tratamiento. \\ Palabras clave: lepra de Wade, lepra histioide, lepra lepromatosa, \\ enfermedad de Hansen. \\ Dermatol. Argent. 2020, 26 (2): 78-80
}

\section{ABSTRACT}

Wade's leprosy or histoid leprosy is a rare variant of this disease, with distinct clinical, bacteriological, and histopathological findings. The presence of lepromas of considerable size, a high bacillary index, and fusiform histiocytes arranged in a whorled pattern are characteristic. It has been reported to manifest "de novo" or as relapse after long-term dapsone monotherapy, inadequate schemes, and also after successful treatments. We present a case of Wade's leprosy without a prior history of any antileprosy treatment.

Key words: Wade's leprosy, histoid leprosy, lepromatous leprosy, Hansen's disease.

Dermatol. Argent. 2020, 26 (2): 78-80
1 Residente de Dermatología

2 Jefa, Unidad de Dermatología

${ }^{3}$ Exjefa de Residentes de Dermatología

${ }^{4}$ Exjefe, Unidad de Lepra

${ }^{5}$ Dermatopatólogo

Unidad de Dermatología, Hospital Dr. F. J. Muñiz, Ciudad Autónoma de Buenos Aires, Argentina
Contacto del autor: Camila Iglesias Leal

E-mail: camiluiglesias@gmail.com

Fecha de trabajo recibido: $20 / 2 / 20$

Fecha de trabajo aceptado: $28 / 5 / 20$

Conflicto de interés: los autores declaran que no existe conflicto de interés.

\section{CASO CLÍ́NICO}

Se presentó a la consulta un hombre de 38 años, oriundo de Misiones, sin antecedentes patológicos ni epidemiológicos de relevancia, debido a una dermatosis generalizada de 5 años de evolución.

En el examen físico se observaban tubérculos de superficie lisa y brillante, eritematosos y color piel, hipertróficos, de forma hemisférica y consistencia duroelástica, algunos umbilicados y otros con necrosis central, dispuestos de forma aislada o agminados en placas, localizados en la cara, con predominio de la nariz y el entrecejo, los pabellones auriculares, el tronco y la región extensora de los miembros, con respeto de los pliegues y la corredera vertebral. Estos alternaban con máculas ferruginosas de límites imprecisos y se asociaban a una alteración de la sensibilidad táctil en la piel sana de las manos y los pies (Fotos 1 y 2 ).

Se realizó una baciloscopia que resultó positiva $(+++)$, con abundantes bacilos íntegros y globis. En la histopatología de uno de los tubérculos se evidenció atrofia epidérmica, una zona acelular subyacente o "muro de contención" y proliferación de histiocitos ahusados dispuestos en fascículos arremolinados en la dermis. La tinción de Ziehl-Neelsen (ZN) mostró abundantes bacilos ácido-alcohol resistentes (BAAR) íntegros (Fotos 3 y 4 ). 
F0T0 1: Tubérculos hipertróficos en la nariz que se agminaban y alteraban la anatomía local.

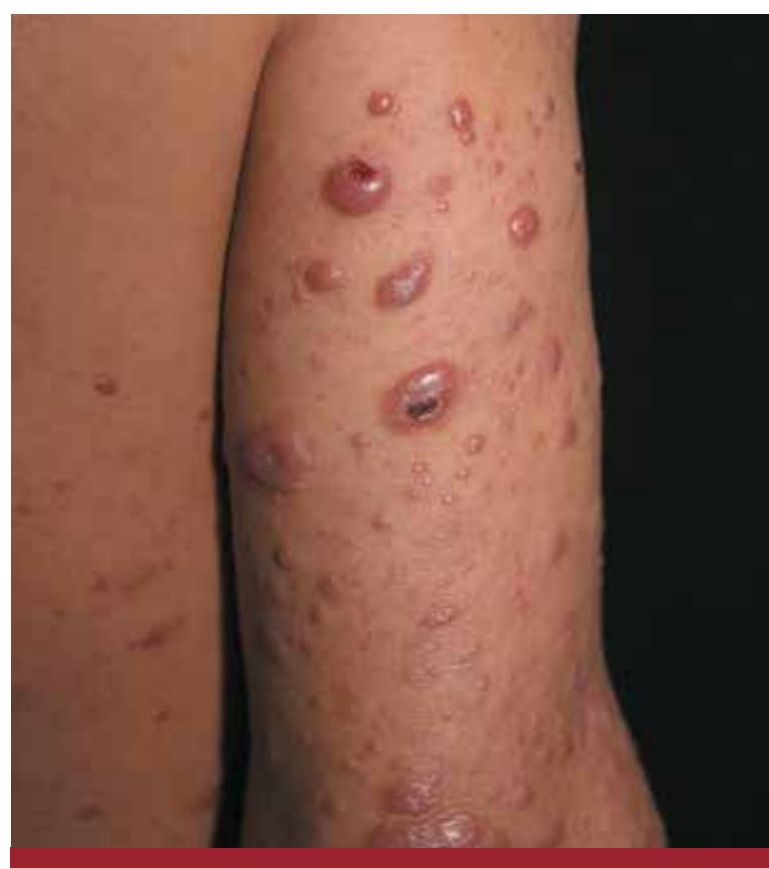

FOTO 2: Tubérculos hipertróficos en la zona extensora de los miembros, algunos ulcerados y otros umbilicados.

Los hallazgos clínicos, baciloscópicos e histopatológicos confirmaron el diagnóstico de LH.

Se inició tratamiento con pulsos mensuales de rifampicina $600 \mathrm{mg}$ + moxifloxacina $400 \mathrm{mg}$ + minociclina 100 mg (RMM). Dos semanas después de la primera toma, el paciente presentó un episodio reaccional de tipo 2, con eritema nodoso asociado a neuritis y elevación de las transaminasas. La ecografía abdominal mostró hepatomegalia
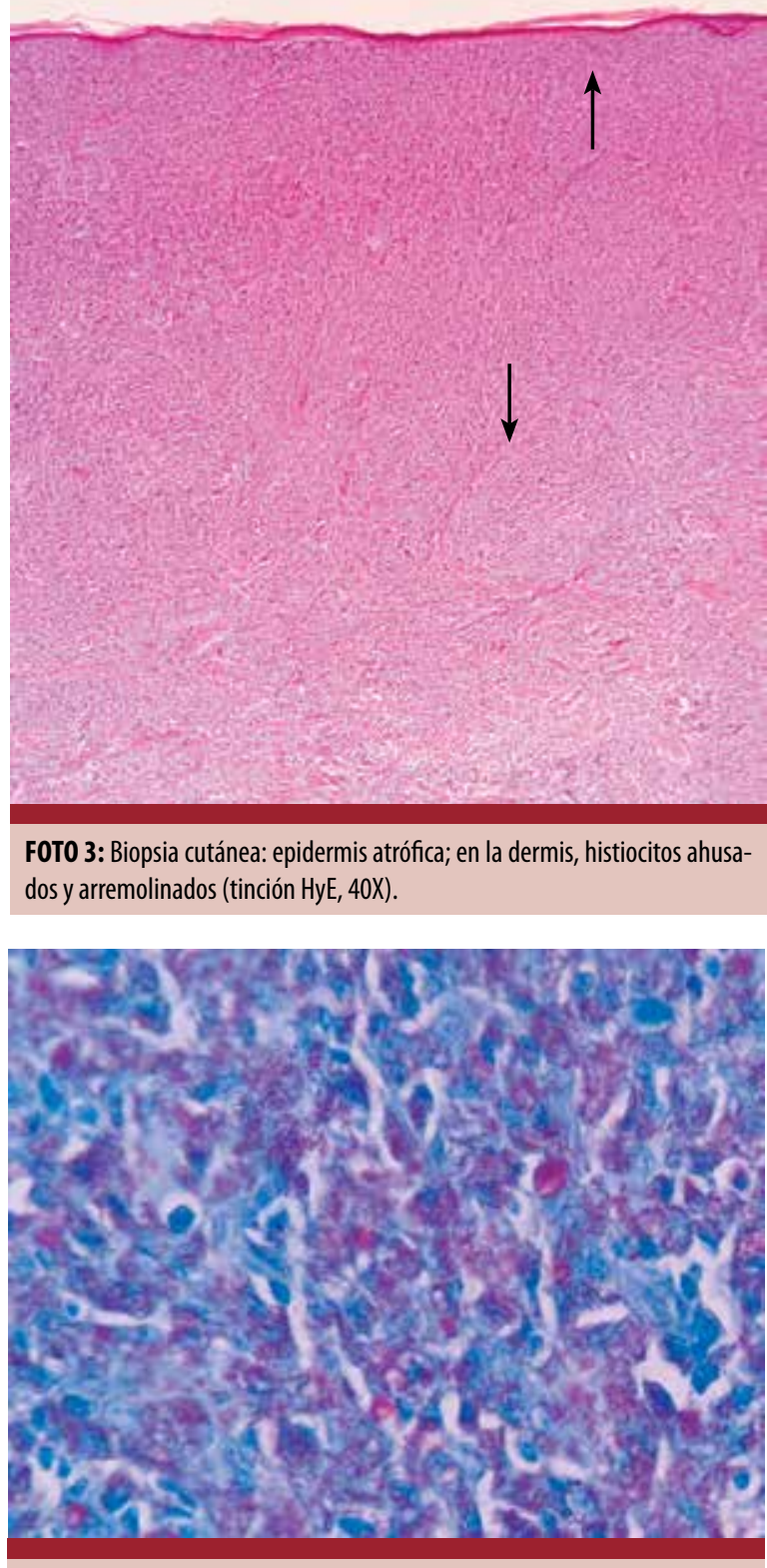

F0T0 4: Abundantes BAAR y globis (tinción de Ziehl-Neelsen, 400X).

con una adenopatía en el ligamento hepatoduodenal. Se indicó tratamiento con meprednisona $40 \mathrm{mg} / \mathrm{d}$ ía, con buena respuesta y descenso escalonado de la dosis.

El paciente tuvo buena evolución clínica, con desinfiltración de los tubérculos y sin nuevos episodios reaccionales después de 16 meses de tratamiento. Si bien esperábamos completar 24 meses de RMM, el paciente interrumpió el seguimiento.

\section{COMENTARIO}

En 1960, Wade describió por primera vez la LH como una variedad poco frecuente de la lepra lepromatosa, caracterizada por la presencia de grandes lepromas compuestos por células histioides, ricos en bacilos y sin globis. 
Su incidencia es baja; en las series de casos publicadas oscila entre $1,12 \%$ ( 8 de 711 ), 1,8\% (40 de 2150) y $2,9 \%$ (11 de 380) de los pacientes con lepra. Es más frecuente en los hombres y la edad en el momento del diagnóstico varía entre 36 y 40 años $^{1-3}$.

La mayoría de los pacientes son lepromatosos y, en menor medida, dimorfos ${ }^{3}$. Clásicamente, la LH se asoció a monoterapias con dapsona o tratamientos incompletos. Hay pacientes sin diagnóstico previo de lepra que no recibieron ningún esquema, como el del caso presentado, interpretado como $\mathrm{LH}$ de novo; y también con la modalidad de recaídas luego de completar el tratamiento multimedicamentoso contra multibacilares de la OMS (MDT-MB). En las publicaciones recientes, estas dos presentaciones son predominantes ${ }^{1-4}$. En las series revisadas, de un total de 3.836 casos de lepra, 72 fueron $\mathrm{LH}$, de los cuales 53 nunca recibieron tratamiento antileproso, 13 fueron recaídas luego de MDT-MB completo, 4 recibieron esquemas incompletos y solo 2 tenían antecedentes de monoterapia con dapsona ${ }^{1-4}$.

La etiopatogenia de esta entidad no está aclarada. Dos factores parecerían estar implicados: la resistencia del agente y la inmunidad del huésped. A favor del primero, se describe la histórica asociación de la monoterapia con dapsona (resistencia secundaria), mientras que en los casos de LH de novo, participa una resistencia primaria de Mycobacterium leprae. Con respecto al huésped, parece haber en la LH una hiperrespuesta inmune contra la micobacteria, demostrada por el hallazgo de un número mayor de linfocitos T CD4 y CD8, linfocitos B y células de Langerhans en el infiltrado de los tubérculos histioides, en comparación con las lesiones lepromatosas clásicas ${ }^{5,6}$. Esto explicaría la ulceración y necrosis de algunas de ellas ${ }^{7}$. La existencia de casos familiares implica también una predisposición genética ${ }^{8}$. Sin embargo, faltan estudios moleculares que confirmen esta teoría.

Clínicamente, la LH se caracteriza por lepromas hemisféricos, rojo violáceos o color piel, firmes e in-

\section{BIBLIOGRAFÍA}

1. Canuto MJM, Yacoub CRD, Trindade MAB, Avancini J, et ál. Histoid leprosy: clinical and histopathological analysis of patients in follow-up in University Clinical Hospital of endemic country. Int J Dermatol 2018;57:707-712.

2. Kaur I, Dogra S, De D, Saikia UN. Histoid leprosy: a retrospective study of 40 cases from India. Br J Dermatol 2009:160:305-310.

3. Mathur M, Jha A, Joshi R, Wagle R. Histoid leprosy: a retrospective clinicopathological study from central Nepal. Int J Dermatol 2017;56:664-668.

4. Palit A, Indmar AC. Histoid leprosy as reservoir of the disease; a challenge to leprosy elimination. Lepr Rev 2007;78:47-49.

5. Da Costa DA, Enokihara MM, Nonogaki S, Maeda SM, et ál. Wade doloros, de gran tamaño, que pueden se umbilicar o ulcerar. Se ubican en cualquier parte del tegumento. Se ubican en cualquier parte del tegumento.

Es infrecuente la infiltración de los lóbulos auriculares, el compromiso mucoso o la presencia de secuelas tróficas ${ }^{2,7}$.

Los resultados de los estudios bacteriológicos muestran índices baciloscópicos y morfológicos altos. Los bacilos son más largos, aislados o agrupados, casi siempre con ausencia de globis, aunque estos pueden hallarse, como en el paciente del caso analizado ${ }^{6,7}$.

La histopatología se define por la atrofia epidérmica, zona de Grenz e histiocitos ahusados dispuestos en un patrón arremolinado o entrecruzado en la dermis y numerosos $\mathrm{BAAR}^{3,7}$.

La incidencia de un episodio reaccional es menor que en la lepra lepromatosa ${ }^{2,6,7}$. No obstante, en nuestro caso y en otras publicaciones, se produjo un episodio de tipo $2^{1,2}$.

La principal dificultad en el diagnóstico diferencial se presenta ante un paciente con LH de novo. Los tubérculos hipertróficos pueden evocar xantomas tuberosos, neurofibromatosis, dermatofibromas, dermatofibrosarcoma protuberante, carcinoma basocelular nodular, tofos gotosos, seudolinfomas, lesiones moluscoides e, incluso, cicatrices queloides. La histología y el hallazgo de BAAR corroboran el diagnóstico ${ }^{1,9}$.

En cuanto al tratamiento, se ha evidenciado una buena respuesta al esquema MDT-MB de la OMS ${ }^{2,3,8}$. Por la posibilidad de resistencia primaria a la dapsona, se prefiere el uso de esquemas alternativos como ROM/RMM (rifampicina $600 \mathrm{mg}+$ ofloxacina/moxifloxacina $400 \mathrm{mg}+$ minociclina $100 \mathrm{mg}$ en tomas mensuales) ${ }^{7}$.

En conclusión, la lepra de Wade es una variedad infrecuente de la enfermedad de Hansen. En la actualidad, tiende a presentarse como recaídas postratamiento MDT$\mathrm{MB}$ completo o de novo como en este caso. Estos últimos representan un desafío diagnóstico que obliga a agudizar la sospecha ante la presencia de tubérculos hipertróficos. Dada su elevada carga bacilar, su tratamiento oportuno es epidemiológicamente significativo.

histoid leprosy: histological and immunohistochemical analysis. Lepr Rev 2013;84:176-185.

6. Sehgal VN, Srivastava G. Status of Histoid Leprosy. A Clinical, Bacteriological, Histopathological and Immunological Appraisal. J Dermatol 1987;14:38-42.

7. Gupta SK. Histoid leprosy: review of the literature. Int J Dermatol 2015;54:1283-1288.

8. Hali F, Benchikhi H, Azzouzi S, Zamiati S, et ál. Lèpre histoïde familiale. Ann Dermatol Venereol 2011;138:42-45.

9. Sehgal VN, Srivastava G, Singh N, Prasad PV. Histoid leprosy: the impact of the entity on the postglobal leprosy elimination era. Int J Dermatol 2009;48:603-610. 